\title{
Photosynthetic induction is slower in young leaves than in mature leaves in a tropical invader, Chromolaena odorata
}

\author{
S.B. ZHANG ${ }^{* * *,+}$, Y.J. HAO ${ }^{* * *}$, and Q.L. DENG ${ }^{\#}$ \\ CAS Key Laboratory of Tropical Forest Ecology, Xishuangbanna Tropical Botanical Garden, Chinese Academy \\ of Sciences, Mengla, 666303 Yunnan, China* \\ Yuanjiang Savanna Ecosystem Research Station, Xishuangbanna Tropical Botanical Garden, Chinese Academy \\ of Sciences, Yuanjiang, 653300 Yunnan, China** \\ School of Ecology and Environment Conservation, Southwest Forestry University, Kunming, 650224 Yunnan, \\ China $^{* * *}$ \\ School of Geography and Eco-tourism, Southwest Forestry University, Kunming, 650224 Yunnan, China
}

\begin{abstract}
Chromolaena odorata is a noxious invasive perennial herb in tropics and subtropics throughout the world. However, photosynthetic induction of this invader is not well understood. Here, we measured the induction of gas exchange and chlorophyll fluorescence in young and mature leaves of Chromolaena odorata. During photosynthetic induction, the young leaves exhibited higher biochemical and total limitations to photosynthesis than that of the mature leaves. Photosynthetic induction in this invader was affected by a mix of biochemical and stomatal limitations. Under a strong photosynthetic photon flux density, nonphotochemical quenching was rapidly activated to dissipate excessive light energy in both young and mature leaves. Furthermore, the induction of photosynthetic electron flow was faster than that of net photosynthetic rate for both young and mature leaves. The rapid activation of nonphotochemical quenching can dissipate excess light energy and regulate photosynthetic electron flow during photosynthetic induction, especially in the young leaves.
\end{abstract}

Additional key words: induction limitation; nonphotochemical quenching; photoprotection; photosynthetic electron flow.

\section{Introduction}

In natural environments, plant leaves are subjected to continuous fluctuations in light levels. Increases in net photosynthetic rate $\left(P_{\mathrm{N}}\right)$ in leaves suddenly exposed to strong light (sunflecks) are not immediate. Instead, $P_{\mathrm{N}}$ gradually increases toward a new steady state. This adaptation process is known as photosynthetic induction (Pearcy 1990). It was estimated that sunflecks account for $60-80 \%$ of PPFD for understory plants (Pearcy 1990, Chazdon 1998). Likewise, in open areas, plant leaves are subjects to fluctuating light levels owing to leaf angle, cloud cover, the movement of leaves above them, and leaf own movement caused by wind (Kaiser et al. 2018). Thus, the efficient utilization of light energy from sunflecks is crucial for maximum carbon gain by plant leaves in natural environments.

Both young and mature leaves are commonly found on the same plant. The juvenile stage is crucial for a leaf expansion; however, young leaves generally have lower light-use efficiency than that of mature leaves. This low light-use efficiency causes the young leaves to be highly vulnerable to photoinhibition (Krause et al. 1995, Bertamini and Nedunchezhian 2003, Ranjan et al. 2014, Zhu et al. 2016, Huang et al. 2017). Steady-state photosynthetic performance and photosynthetic electron flow in young and mature leaves have been compared extensively (Sperdouli and Moustakas 2012, 2015; Yan et al. 2012, Ranjan et al. 2014, Chondrogiannis and Grammatikopoulos 2016, Zhu et al. 2016, Huang et al. 2017, Zhang and Zhang

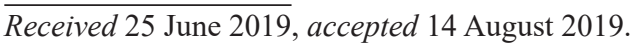

${ }^{+}$Corresponding author; phone: +86 6918713046 , e-mail: zhangshubin@xtbg.ac.cn

Abbreviations: $\mathrm{AQE}$ - apparent quantum efficiency; $\mathrm{BL}$ - biochemical limitation; $\mathrm{Ch} 1$ - chlorophyll; $C_{\mathrm{i}}$ - intercellular $\mathrm{CO}_{2}$ concentration; $\mathrm{F}_{\mathrm{s}}$ - steady-state fluorescence yield; $\mathrm{F}_{\mathrm{v}} / \mathrm{F}_{\mathrm{m}}$ - maximum quantum yield of PSII photochemistry; $\mathrm{F}_{\mathrm{v}}{ }^{\prime} / \mathrm{F}_{\mathrm{m}}{ }^{\prime}-$ maximum quantum yield of PSII after light adaptation; $g_{\mathrm{s}}$ - stomatal conductance; $\mathrm{J}_{\max }$ - maximum rate of RuBP regeneration; $\mathrm{J}_{\mathrm{T}}$ - total electron flow through PSII; $\mathrm{L}_{\text {abs }}$ - leaf absorption at wavelengths from 400 to $700 \mathrm{~nm}$; LSP - light-saturation point; ML - mature leaf; NPQ - nonphotochemical quenching; $P_{\mathrm{N}}-$ net photosynthetic rate; $P_{\mathrm{N}}{ }^{*}$ - photosynthetic rate without stomatal limitation; $P_{\mathrm{Nmax}}-$ light-saturated net photosynthetic rate; $\mathrm{q}_{\mathrm{N}}$ - nonphotochemical quenching coefficient; $\mathrm{q}_{\mathrm{P}}$ - photochemical quenching coefficient; $R_{\mathrm{D}}$ - respiration rate; ROS - reactive oxygen species; RuBP - ribulose-1,5-bisphosphate; SL - stomatal limitation; SPAD - chlorophyll content per unit leaf using a portable chlorophyll meter; $\mathrm{T}_{90-\mathrm{gs}}$ - the time required to reach $90 \%$ of maximum $g_{\mathrm{s}} ; \mathrm{T}_{90-\mathrm{JT}}$ - the time required to reach $90 \%$ of maximum $\mathrm{J}_{\mathrm{T}}$; $\mathrm{T}_{90-\mathrm{PN}}$ - the time required to reach $90 \%$ of $P_{\mathrm{Nmax}} ; \mathrm{TL}$ - total limitation to photosynthesis; $\mathrm{V}_{\text {cmax }}$ - maximum rate of RuBP carboxylation; $\mathrm{YL}$ - young leaf; $\Phi_{\mathrm{NPQ}}$ - proportion of dissipation of excess light energy via heat; $\Phi_{\mathrm{PSII}}$ - effective quantum yield of PSII photochemistry. Acknowledgements: This study was funded by the National Natural Science Foundation of China $(31600479,41861144016)$, the CAS Scholarship for visiting research (2018-24), and the CAS 'Light of West China' Program to Shubin Zhang.
} 
2017); however, the differential effects of dynamic light intensity on these leaves have not yet been explored. In addition, while the previous studies on photosynthetic induction have focused on mature leaves (Tausz et al. 2005, Bai et al. 2008, Chen et al. 2014, Soleh et al. 2016), photosynthetic induction in juvenile leaves has received only a limited attention. Therefore, the dynamic photosynthetic performance of the young leaves is not well understood. In order to better understand photosynthetic induction during leaf expansion, we need to measure the photosynthetic response of young leaves to sunflecks.

When a leaf is exposed to a sudden increase in sunlight, $P_{\mathrm{N}}$ is affected by both stomatal and biochemical limitations (Woodrow and Mott 1989, Allen and Pearcy 2000). Photosynthetic induction involves stomatal opening, the activation of Rubisco, and the activation state of ribulose-1,5-bisphosphate $(\mathrm{RuBP})$ regeneration (Pearcy and Seemann 1990, Chazdon 1998). In leaves placed in shade or darkness for an extended period, Rubisco and other photosynthetic enzymes are deactivated, resulting in a small pool of Calvin cycle intermediates (Tausz et al. 2005). During photosynthetic induction, the gradual activation of photosynthetic enzymes slowly eliminates the biochemical limitations to photosynthesis (Tausz et al. 2005, Kobayashi and Masuda 2007, Urban et al. 2008). Similarly, it takes some time for stomata to achieve high stomatal conductance $\left(g_{\mathrm{s}}\right)$ when leaves experience a change from darkness or shade to sudden high-intensity light, where stomatal limitations (SL) increase as a result of limited $\mathrm{CO}_{2}$ supplies in chloroplasts (Tausz et al. 2005). Thus, plant leaves must overcome both stomatal and biochemical limitations (BL) to photosynthesis before achieving a new steady state when exposed to sunflecks.

The light intensities to which leaves are exposed vary from shade to full sunlight over a variety of temporal scales, where changes may occur even within $1 \mathrm{~s}$ (Pearcy et al. 1997, Chen et al. 2014). Owing to biochemical and stomatal limitations, there is a time lag between the onset of a sunfleck and maximum $P_{\mathrm{N}}$ (Allen and Pearcy 2000, Tausz et al. 2005, Yamori 2016), while the actual photochemical efficiency of PSII $\left(\Phi_{\mathrm{PSII}}\right)$ is near zero during the first 1-2 min of exposure to a strong sunfleck (Tausz et al. 2005). Therefore, sunflecks may result in excess excited electrons that are not used for photochemistry, which could lead to photoinhibition (Watling et al. 1997, Tausz et al. 2005, Bai et al. 2008).

Plant leaves have various photoprotective mechanisms to cope with excess light energy from strong sunflecks, such as avoiding exposure to light, nonphotochemical quenching (NPQ), and photorespiratory pathways (Watling et al. 1997, Tausz et al. 2005, Huang et al. 2015, Chen et al. 2016, Yamori 2016). The rapid activation of NPQ largely dissipates the excess light energy absorbed during sunflecks (Tausz et al. 2005, Watling et al. 1997). The activation of NPQ is accompanied by a high proton gradient across the thylakoid membrane $(\Delta \mathrm{pH})$ (Munekage et al. 2002, 2004). This $\Delta \mathrm{pH}$-dependent quenching $\left(\mathrm{q}_{\mathrm{E}}\right)$ can prevent overreduction of the plastoquinone pool (Yamori 2016). The upregulation of NPQ also maintains the stability of photosynthetic machinery under strong light (Müller and Niyogi 2001). Moreover, photorespiration regulates photosynthetic electron flow and $P_{\mathrm{N}}$ under fluctuating light levels in tobacco plants (Huang et al. 2015). It was also suggested that cyclic electron flows around PSI (CEF-PSI) have physiological roles in sustaining photosynthesis and plant growth under repeated light fluctuations (Joliot and Johnson 2011, Yamori et al. 2016).

Chromolaena odorata (L.) R. M. King and H. Robinson (Asteraceae), native to Central and South America, was introduced to other tropical areas in the middle of the $19^{\text {th }}$ century (Qin et al. 2013). This invasive species, as a light-demanding species, mainly distributed in open habitats, such as farmlands, forest gaps, and road sides. This light-demanding invader exhibits high photosynthetic performance and a rapid growth rate. It formed dense monodominant stands and influenced the growth of native species in invaded areas, which severely damaged agriculture, forestry, biodiversity, and environments of invaded areas (Raimundo et al. 2007). It became a noxious invasive perennial herb in much of the tropics and subtropics throughout the world (Zheng et al. 2015). It is well known that photosynthetic performance could contribute to the success of this invasive species (Quan et al. 2015). Photosynthetic traits related to carbon gain can directly influence plant fitness, and an invader's strategy of competition (McAlpine et al. 2008). It is well known that photosynthesis under fluctuating light may contribute to carbon gain, and therefore plant fitness (Pearcy 1990, Pearcy et al. 1996). Thus, it is important to study the photosynthetic responses to sunflecks in this invader. Furthermore, the result of such test will give an important reference for estimation of photosynthetic behaviour of other light-demanding invasive species.

In this study, we investigated the induction of gas exchange and chlorophyll (Chl) fluorescence in the young and mature leaves of $C$. odorata and addressed the following questions: (1) Does the induction of photosynthesis differ between young and mature leaves? We hypothesized that young leaves would display slower rates of photosynthetic induction than that of the mature leaves. (2) Is NPQ activated rapidly when leaves are exposed to a sudden increase in light intensity? During induction, the initial photochemical efficiency is very low owing to considerable limitations to photosynthesis (Tausz et al. 2005). We therefore hypothesized that the rapid activation of NPQ would dissipate excess light energy in response to strong PPFDs.

\section{Materials and methods}

Study site and plant material: The study was conducted at the Yuanjiang Savanna Ecosystem Research Station, Xishuangbanna Tropical Botanical Garden, Chinese Academy of Sciences in Yunnan, China $\left(23^{\circ} 27^{\prime} \mathrm{N}, 102^{\circ} 10^{\prime} \mathrm{E}\right.$, altitude $481 \mathrm{~m})$. C. odorata seedlings, which were one month old and $\sim 20 \mathrm{~cm}$ in height, were planted in plastic pots (30 $\mathrm{cm}$ in diameter and $50 \mathrm{~cm}$ in height) on 26 May 2016. Throughout the experiment, the plants were cultivated in a greenhouse under naturally fluctuating light, temperature, and relative humidity. The maximum PPFD 
was 2,200 $\mu$ mol(photon) $\mathrm{m}^{-2} \mathrm{~s}^{-1}$ at midday. The mean day/night temperature was $33 / 23^{\circ} \mathrm{C}$ with a mean relative humidity of $60 \%$. The plants were fertilized and irrigated to ensure that nutrients and water were not limiting. During the experiment (7-14 September 2016), the plants were in the middle of a vegetative period. Photosynthesis was measured in newly expanding young leaves (one month old, YLs) and fully expanded mature leaves (three months old, MLs). The leaf area of YLs was approximately 30\% of the leaf area of MLs.

Light- and $\mathrm{CO}_{2}$-response curves were measured using a LI-6400XT photosynthesis system with the standard $2 \times 3 \mathrm{~cm}$ chamber. The upper half of the standard leaf chamber was replaced with a 6400-02B Red/Blue LED Light Source ( $\mathrm{Li}$-Cor, Lincoln, NE, USA). The leaves were enclosed in the chamber until steady-state $P_{\mathrm{N}}$ was obtained under the following conditions: a saturating PPFD of 2,000 $\mu \mathrm{mol}$ (photon) $\mathrm{m}^{-2} \mathrm{~s}^{-1}$, leaf temperature of $25^{\circ} \mathrm{C}$, and $\mathrm{CO}_{2}$ concentration of $400 \mu \mathrm{mol}\left(\mathrm{CO}_{2}\right) \mathrm{mol}^{-1}$ controlled by a 6400-01 $\mathrm{CO}_{2}$ Injector System ( $\mathrm{Li}$-Cor, Lincoln, NE, USA). Then, light-response curves $\left(P_{\mathrm{N}} / \mathrm{PPFD}\right)$ were generated from measurements obtained at 2,000; 1,500; 1,$000 ; 500,200,100,50,20$, and $0 \mu \mathrm{mol}$ (photon) $\mathrm{m}^{-2} \mathrm{~s}^{-1}$. Steady-state photosynthesis was maintained for at least 3 min under each PPFD. $P_{\mathrm{N}} /$ PPFD curves were fitted using a nonrectangular hyperbola (Prioul and Chartier 1977). The light-saturation point (LSP) and light-saturated net photosynthetic rate $\left(P_{\mathrm{Nmax}}\right)$ were calculated using PHOTOSYN ASSISTANT software (version 1.0, Li-COR, $2 / 2008$ ). Under low light levels, $P_{\mathrm{N}}$ is linearly correlated with light intensity (Zhang et al. 2009). Dark respiration $\left(R_{\mathrm{D}}\right)$ was calculated based on the $P_{\mathrm{N}} / \mathrm{PPFD}$ values obtained for PPFDs of 20-100 $\mu$ mol(photon) $\mathrm{m}^{-2} \mathrm{~s}^{-1}$. The response curves of $P_{\mathrm{N}}$ to intercellular $\mathrm{CO}_{2}$ concentration $\left(P_{\mathrm{N}} / C_{\mathrm{i}}\right.$ curves) were made by maintaining a PPFD of 2,000 $\mu \mathrm{mol}$ (photon) $\mathrm{m}^{-2} \mathrm{~s}^{-1}$ and varying the $\mathrm{CO}_{2}$ concentration in the chamber. $\mathrm{CO}_{2}$ concentrations were tested in the following orders: 400, 200, 100, 50, 800, 1,200; 1,600; $2,000 \mu \mathrm{mol}\left(\mathrm{CO}_{2}\right) \mathrm{mol}^{-1}$. The maximum rates of $\mathrm{RuBP}$ regeneration $\left(\mathrm{J}_{\max }\right)$ and RuBP carboxylation $\left(\mathrm{V}_{\text {cmax }}\right)$ were calculated from the $P_{\mathrm{N}} / \mathrm{C}_{\mathrm{i}}$ curves according to Long and Bernacchi (2003).

Photosynthetic induction: Gas exchange and chlorophyll (Chl) fluorescence during photosynthetic induction were measured simultaneously using a LI-6400XT photosynthesis system, with a fluorometer chamber (Licor-6400-40, $\mathrm{Li}$-Cor, Lincoln, NE, USA). Before measurements, plants were kept in a dark room overnight. As the first step of Rubisco relaxation may occur in deep shade, a preillumination of $50 \mu \mathrm{mol}$ (photon) $\mathrm{m}^{-2} \mathrm{~s}^{-1}$ was used for $5 \mathrm{~min}$ for leaves at low light intensity (Jackson et al. 1991, Soleh et al. 2016). After preillumination, PPFD was increased to 2,000 $\mu \mathrm{mol}$ (photon) $\mathrm{m}^{-2} \mathrm{~s}^{-1}$ in one step, and photosynthetic induction was measured for $30 \mathrm{~min}$ at a leaf temperature of $25^{\circ} \mathrm{C}$ and relative humidity of $60 \% . P_{\mathrm{N}}, g_{\mathrm{s}}$, and $C_{\mathrm{i}}$ were recorded at 1-min intervals using the $L I-6400 X T$ auto-log program. The time required to reach $90 \%$ of $P_{\mathrm{Nmax}}\left(\mathrm{T}_{90-\mathrm{PN}}\right)$ and maximum $g_{\mathrm{s}}\left(\mathrm{T}_{90-\mathrm{gs}}\right)$ was calculated as described by
Tausz et al. (2005).

Leaves, which were dark-adapted overnight, were used to determine ground fluorescence yield $\left(\mathrm{F}_{0}\right)$, and maximum fluorescence yield $\left(\mathrm{F}_{\mathrm{m}}\right)$ was subsequently measured using a 0.8 -s saturating pulse of 7,000 $\mu \mathrm{mol}$ (photon) $\mathrm{m}^{-2} \mathrm{~s}^{-1}$. During photosynthetic induction, minimum $\left(\mathrm{F}_{0}{ }^{\prime}\right)$ and maximum $\mathrm{Chl}$ fluorescence $\left(\mathrm{F}_{\mathrm{m}}{ }^{\prime}\right)$ of light-adapted leaves were recorded at 1-min intervals, as was steady-state fluorescence under actinic light $\left(\mathrm{F}_{\mathrm{s}}\right)$. Photosynthetic induction is not affected by frequent saturation pulses (Yamori et al. 2012). The photochemical quenching coefficient $\left(\mathrm{q}_{\mathrm{p}}\right)$, actual photochemical efficiency of PSII $\left(\Phi_{\mathrm{PSI}}\right)$, and proportion of dissipation of excess light energy via heat $\left(\Phi_{\mathrm{NPQ}}\right)$ were calculated according to the following formulas (Genty et al. 1989): $\mathrm{q}_{\mathrm{P}}=\left(\mathrm{F}_{\mathrm{m}}{ }^{\prime}-\mathrm{F}_{\mathrm{s}}\right) /\left(\mathrm{F}_{\mathrm{m}}{ }^{\prime}-\mathrm{F}_{0}{ }^{\prime}\right), \Phi_{\mathrm{PSII}}=$ $1-\left(\mathrm{F}_{\mathrm{s}}-\mathrm{F}_{\mathrm{m}}{ }^{\prime}\right), \Phi_{\mathrm{NPQ}}=\left(\mathrm{F}_{\mathrm{s}} / \mathrm{F}_{\mathrm{m}}{ }^{\prime}\right)-\left(\mathrm{F}_{\mathrm{s}} / \mathrm{F}_{\mathrm{m}}\right)$.

Photosynthetic electron flow: The total electron flow $\left(\mathrm{J}_{\mathrm{T}}\right)$ during photosynthetic induction was estimated according to the following formula (Krall and Edwards 1992): $\mathrm{J}_{\mathrm{T}}=0.5 \times \mathrm{L}_{\mathrm{abs}} \times$ PPFD $\times \Phi_{\text {PSII. }}$. The absorbed photons were assumed to distribute equally in PSI and PSII, and thus the factor 0.5 was applied to the calculation of electron flow. Leaf absorption ( $\left.\mathrm{L}_{\text {abs }}\right)$ was measured using a USB-4000 spectrometer (Ocean Optics, Florida, USA) at wavelengths from 400 to $700 \mathrm{~nm}$. The average values of $\mathrm{L}_{\text {abs }}$ were $0.863 \pm 0.004$ and $0.905 \pm 0.003$ in YLs and MLs, respectively.

Induction limitations: Stomatal and biochemical limitations during photosynthetic induction were evaluated according the model proposed by Woodrow and Mott (1989). In this model, photosynthetic rate without stomatal limitation $\left(P_{\mathrm{N}}^{*}\right)$ was estimated by assuming that $C_{\mathrm{i}}$ maintained a constant value: $P_{\mathrm{N}}{ }^{*}=\left\{\left[\left(P_{\mathrm{N}}+R_{\mathrm{D}}\right)\left(C_{\mathrm{if}}-\Gamma^{*}\right)\right] /\right.$ $\left.\left(C_{\mathrm{i}}-\Gamma^{*}\right)\right\}-R_{\mathrm{D}}$, where $P_{\mathrm{N}}$ and $R_{\mathrm{D}}$ during photosynthetic induction are described above, $C_{\mathrm{i}}$ is the intercellular $\mathrm{CO}_{2}$ concentration, and $C_{\mathrm{if}}$ is the $C_{\mathrm{i}}$ value at the end of photosynthetic induction, $\Gamma^{*}$ is the $\mathrm{CO}_{2}$ compensation concentration in the absence of photorespiration, and was assumed to be 32.2 at $25^{\circ} \mathrm{C}$ (Farquhar et al. 1980). $\mathrm{SL}$ and BL were calculated as follows: $\mathrm{SL}=\left(P_{\mathrm{N}}{ }^{*}-P_{\mathrm{N}}\right) /$ $\left(P_{\mathrm{N} \max }+R_{\mathrm{D}}\right), \mathrm{BL}=\left(P_{\mathrm{N} \max }-P_{\mathrm{N}}^{*}\right) /\left(P_{\mathrm{N} \max }+R_{\mathrm{D}}\right)$, where $P_{\mathrm{N} \max }$ is the maximum $P_{\mathrm{N}}$ at the end of photosynthetic induction. The total limitation to photosynthesis (TL) is calculated as the sum of SL and BL.

Rubisco and Chl content: The Rubisco contents of leaves were estimated according to the method described by Yamori et al. (2010): $\mathrm{y}=35.3 \mathrm{x}+6.6$, where $\mathrm{y}$ is $\mathrm{V}_{\mathrm{cmax}}\left[\mu \mathrm{mol}\right.$ (photon) $\left.\mathrm{m}^{-2} \mathrm{~s}^{-1}\right]$ and $\mathrm{x}$ is Rubisco content $\left(\mu \mathrm{mol} \mathrm{m} \mathrm{m}^{-2}\right)$. This regression equation was generated at $25^{\circ} \mathrm{C}$ from tobacco leaves. This estimation might not correspond to the actual Rubisco content, however, it can indicate the relative content of activated Rubisco. The Chl content per unit leaf (SPAD) was estimated using a portable chlorophyll meter (SPAD-502, Minolta Camera Co., Ltd., Japan).

Statistical analyses were performed using SPSS 16.0 for 
Windows (SPSS Inc., Chicago, IL, USA). The results were displayed as means $\pm \operatorname{SE}(n=6)$. Independent $t$-tests were used to evaluate the differences between YLs and MLs $(P<0.05)$.

\section{Results}

Steady-state gas-exchange parameters: At PPFDs above $200 \mu \mathrm{mol}\left(\right.$ photon) $\mathrm{m}^{-2} \mathrm{~s}^{-1}$, MLs exhibited significantly higher $P_{\mathrm{N}}$ than that of YLs (Fig. 1A). Similarly, when $C_{\mathrm{i}}$ was more than $100 \mu \mathrm{mol}\left(\mathrm{CO}_{2}\right) \mathrm{mol}^{-1}$ at a PPFD of 2,000 $\mu \mathrm{mol}$ (photon) $\mathrm{m}^{-2} \mathrm{~s}^{-1}, P_{\mathrm{N}}$ was higher in MLs than that in YLs (Fig. 1B). MLs also displayed significantly higher LSP, $P_{\text {Nmax }}, \mathrm{V}_{\text {cmax }}$, and $\mathrm{J}_{\max }$ than that of YLs (Table 1), which indicated that MLs had a higher steadystate photosynthetic capacity. In addition, YLs had significantly lower estimated Rubisco and Chl contents (SPAD values) than that of MLs (Table 1).

Characteristics of photosynthetic induction: Photosynthetic induction differed between YLs and MLs when PPFD increased suddenly from 50 to 2,000 $\mu$ mol(photon) $\mathrm{m}^{-2} \mathrm{~s}^{-1}$ (Fig. 2). $P_{\mathrm{N}}$ and $g_{\mathrm{s}}$ increased gradually for both YLs and MLs, and the induction curves followed a sigmoidal pattern. $P_{\mathrm{N}}$ and $g_{\mathrm{s}}$ increased more rapidly in MLs than that in YLs (Fig. 2A,B). Accordingly, MLs exhibited higher values of $C_{\mathrm{i}}$ than that of YLs at both low and high light levels (Fig. 2C).

When exposed to a PPFD of $50 \mu \mathrm{mol}$ (photon) $\mathrm{m}^{-2} \mathrm{~s}^{-1}$ for $5 \mathrm{~min}, g_{\mathrm{s}}$ did not differ significantly between YLs and MLs (Fig. 2B, Table 2). This result showed that the initial stomatal conductance $\left(g_{\text {s-initial }}\right)$ during photosynthetic induction was similar for both YLs and MLs. After exposure to 2,000 $\mu \mathrm{mol}$ (photon) $\mathrm{m}^{-2} \mathrm{~s}^{-1}$ for $30 \mathrm{~min}$, MLs displayed a significantly higher maximum $g_{\mathrm{s}}\left(g_{\mathrm{s}-\max }\right)$ than that of YLs (Fig. 2B, Table 2). However, the time required to reach $90 \%$ of maximum stomatal conductance $\left(\mathrm{T}_{90-\mathrm{gs}}\right)$ was not significantly different between MLs and YLs (Table 2). During photosynthetic induction, $P_{\mathrm{N}}$ increased quickly, and after 20 min was at a near-steady-state value. However, significantly less time was required to reach $90 \%$ of $P_{\text {Nmax }}\left(T_{90-\mathrm{PN}}\right)$ in MLs than that in YLs (Table 2). This indicated that full photosynthetic induction was reached more quickly in MLs than in YLs.

Photochemistry and photosynthetic electron flow: During photosynthetic induction, $\mathrm{q}_{\mathrm{P}}$ and $\Phi_{\mathrm{PSII}}$ increased gradually for both YLs and MLs. However, $\mathrm{q}_{\mathrm{P}}$ and $\Phi_{\mathrm{PSII}}$ were higher for MLs than that for YLs (Fig. 3A,B). In response to a strong $\mathrm{PPFD}, \Phi_{\mathrm{NPQ}}$ decreased slightly from

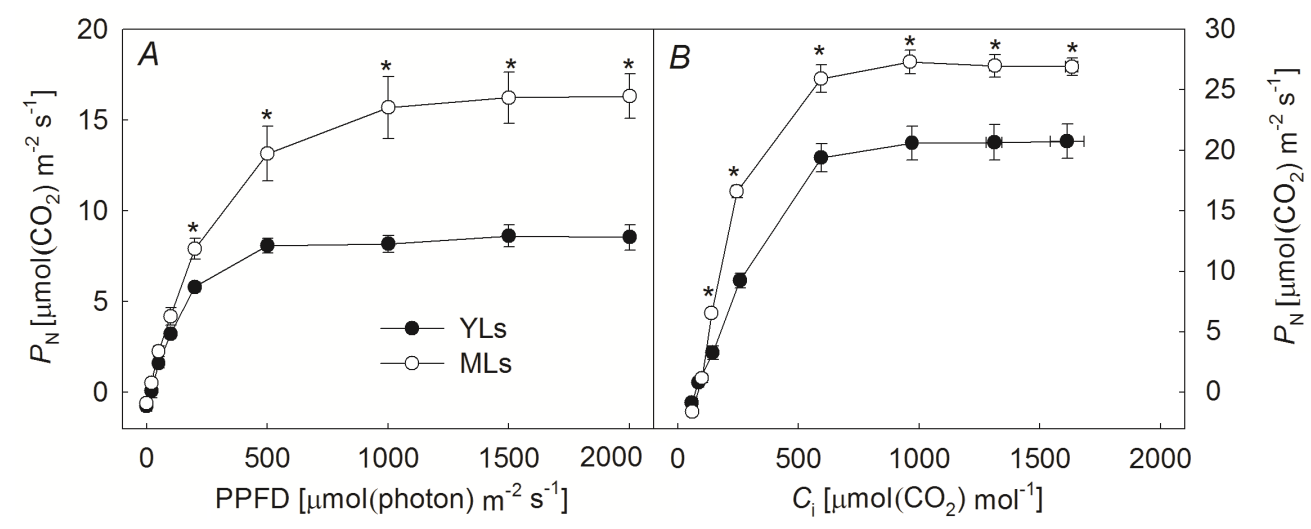

Fig. 1. Response curves of net photosynthetic rate $\left(P_{\mathrm{N}}\right)$ to incident photosynthetic photon flux density (PPFD) $(A)$ and intercellular $\mathrm{CO}_{2}$ concentration $\left(C_{\mathrm{i}}\right)(B)$ in young and mature Chromolaena odorata leaves. Significant differences between young leaves (YLs) and mature leaves (MLs) are indicated by asterisks (independent $t$-test at $P<0.05)$. Values are means $\pm \operatorname{SE}(n=6)$.

Table 1. Comparisons of photosynthetic parameters under steady-state conditions, Rubisco content, and chlorophyll content in the young and mature leaves of Chromolaena odorata. Values are means $\pm \operatorname{SE}(n=6)$. The differences between young leaves and mature leaves were tested by independent $t$-test $(P<0.05)$. $\mathrm{J}_{\max }-$ maximum rate of RuBP regeneration; LSP - light-saturation point; $P_{\mathrm{Nmax}}-$ lightsaturated net photosynthetic rate; $R_{\mathrm{D}}$ - respiration rate; SPAD - chlorophyll content per unit leaf using a portable chlorophyll meter; $\mathrm{V}_{\mathrm{cmax}}$ - maximum rate of RuBP carboxylation.

\begin{tabular}{lllc}
\hline Parameters & Young leaves & Mature leaves & Significance \\
\hline LSP $\left[\mu \mathrm{mol}(\right.$ photon$\left.) \mathrm{m}^{-2} \mathrm{~s}^{-1}\right]$ & $560.7 \pm 48.6$ & $1060.7 \pm 69.1$ & $<0.001$ \\
$P_{\text {Nmax }}\left[\mu \mathrm{mol}\left(\right.\right.$ photon $\left.\mathrm{m}^{-2} \mathrm{~s}^{-1}\right]$ & $9.5 \pm 0.5$ & $17.2 \pm 1.5$ & 0.001 \\
$R_{\mathrm{D}}\left[\mu \operatorname{mol}(\right.$ photon$\left.) \mathrm{m}^{-2} \mathrm{~s}^{-1}\right]$ & $0.88 \pm 0.30$ & $0.58 \pm 0.11$ & 0.371 \\
$\mathrm{~V}_{\text {cmax }}\left[\mu \operatorname{mol}(\right.$ photon$\left.) \mathrm{m}^{-2} \mathrm{~s}^{-1}\right]$ & $34.4 \pm 2.0$ & $44.0 \pm 1.7$ & 0.004 \\
$\mathrm{~J}_{\max }\left[\mu \operatorname{mol}(\right.$ photon$\left.) \mathrm{m}^{-2} \mathrm{~s}^{-1}\right]$ & $27.5 \pm 1.6$ & $34.5 \pm 1.0$ & 0.005 \\
Rubisco content $\left[\mathrm{g} \mathrm{m}^{-3}\right]$ & $0.81 \pm 0.06$ & $1.08 \pm 0.05$ & 0.004 \\
SPAD & $35.3 \pm 0.6$ & $45.4 \pm 1.0$ & $<0.001$ \\
\hline
\end{tabular}


0.71 (initial) to 0.66 (end of photosynthetic induction) in MLs. In contrast, $\Phi_{\mathrm{NPQ}}$ remained nearly constant at $\sim 0.71$ in YLs (Fig. 3C).

After the leaves acclimated to $50 \mu \mathrm{mol}\left(\right.$ photon) $\mathrm{m}^{-2} \mathrm{~s}^{-1}$ for $5 \mathrm{~min}$, there was no difference in $\mathrm{J}_{\mathrm{T}}$ between YLs and MLs (Fig. 3D). Under a strong PPFD, $\mathrm{J}_{\mathrm{T}}$ increased

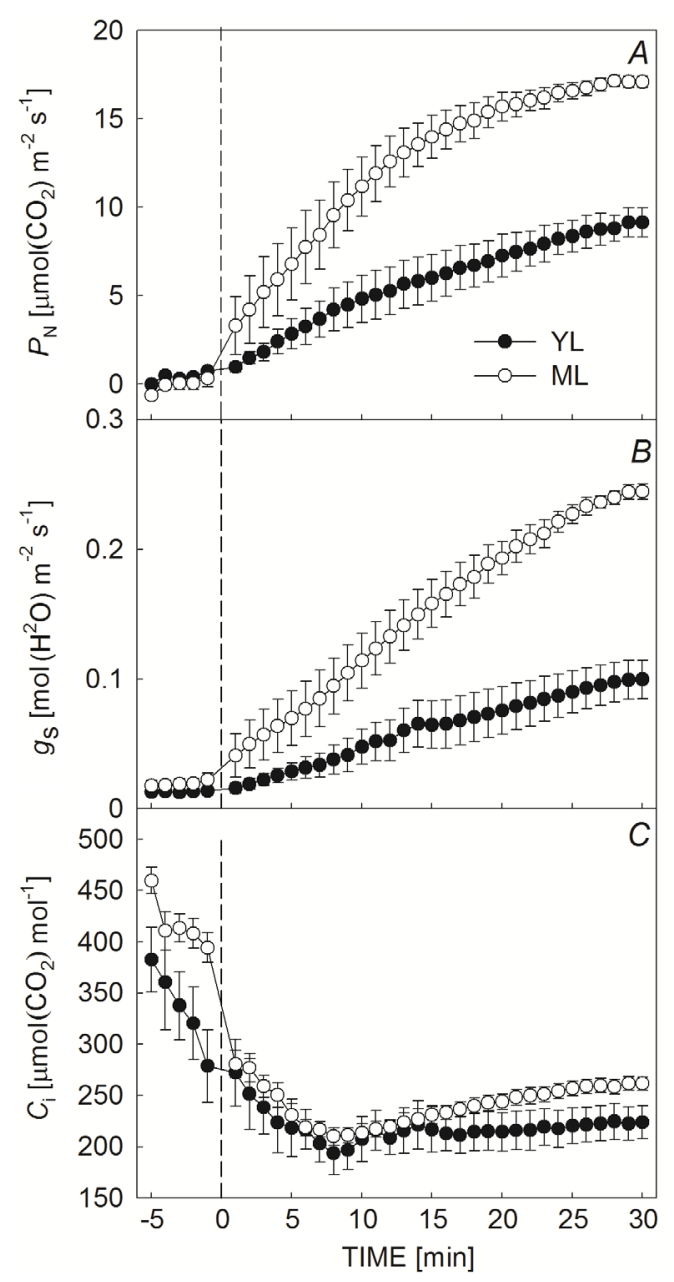

Fig. 2. Comparisons of net photosynthetic rate $\left(P_{\mathrm{N}}\right)(A)$, stomatal conductance $\left(g_{\mathrm{s}}\right)(B)$, and intercellular $\mathrm{CO}_{2}$ concentration $\left(C_{\mathrm{i}}\right)(C)$ during photosynthetic induction in young leaves (YLs) and mature leaves (MLs) of Chromolaena odorata. Values are means $\pm \operatorname{SE}(n=6)$ gradually both for YLs and MLs. However, maximum $\mathrm{J}_{\mathrm{T}}$ was reached more rapidly in MLs than that in YLs, and significantly less time was required to reach $90 \%$ of maximum $\mathrm{J}_{\mathrm{T}}\left(\mathrm{T}_{90-\mathrm{JT}}\right)$ in MLs in comparison to YLs (Table 2).

Induction limitations: After exposure to a strong PPFD, changes in SL and BL exhibited different trends. SL increased and reached a maximum value within 8 and $10 \mathrm{~min}$ for YLs and MLs, respectively, after which decreased gradually in both types of leaves (Fig. 4A). BL and TL decreased gradually, where YLs exhibited higher $\mathrm{BL}$ and TL values than that of MLs (Fig. 4B,C).

\section{Discussion}

\section{Young leaves displayed slower photosynthetic induction than mature leaves}

Our results showed that the light-demanding invader had long $\mathrm{T}_{90-\mathrm{PN}}$ for both YLs and MLs (22.8 and $16.0 \mathrm{~min}$, Table 2). The induction time was much longer than those of the plants grown in open forest canopy or deforested open sites (Bai et al. 2008). This invader is distributed in open habitats, such as farmland, forest gaps, and road sides. There are more frequent fluctuations in light levels in the forest understory. It was estimated that $60-80 \%$ of photosynthetic utilization light for understory plants came from sunflecks (Pearcy 1990, Chazdon 1998). Thus, this light-demanding invader may not adapt to the light environment in forest understory with low light and more frequent sunflecks.

In response to a strong PPFD, photosynthetic induction was much slower in YLs than that in MLs (Fig. 2A). Long photosynthetic induction times have been attributed to low initial $g_{\mathrm{s}}$ (Way and Pearcy 2012). Under a PPFD of $50 \mu \mathrm{mol}\left(\right.$ photon) $\mathrm{m}^{-2} \mathrm{~s}^{-1}$ for $5 \mathrm{~min}, g_{\mathrm{s}}$ did not differ significantly between YLs and MLs (Fig. 2B, Table 2). Therefore, the observed differences in photosynthetic induction between YLs and MLs were not affected by the initial $g_{\mathrm{s}}$ in our studied species. To an extent, transient stomatal limitation exists during photosynthetic induction. SL increased during the initial induction and the maximum values of SL were $12.1 \%$ at $8 \mathrm{~min}$ and $17.1 \%$ at $10 \mathrm{~min}$ from the onset of induction for YLs and MLs, respectively. Then SL decreased till the end of induction (Fig. 4A). Likewise,

Table 2. Comparisons of photosynthetic parameters during photosynthetic induction in the young and mature leaves of Chromolaena odorata. Values are means $\pm \mathrm{SE}(n=6)$. The differences between young leaves and mature leaves were tested by independent $t$-test $(P<0.05)$. $g_{\text {s-initial }}$ - initial stomatal conductance; $g_{\text {s-max }}$ - maximum stomatal conductance; $\mathrm{T}_{90 \text {-gs }}-$ the time required to reach $90 \%$ of maximum $g_{\mathrm{s}} ; \mathrm{T}_{90-\mathrm{JT}}$ - the time required to reach $90 \%$ of maximum $\mathrm{J}_{\mathrm{T}} ; \mathrm{T}_{90-\mathrm{PN}}$ - the time required to reach $90 \%$ of $P_{\mathrm{Nmax}}$.

\begin{tabular}{lllc}
\hline Parameters & Young leaves & Mature leaves & Significance \\
\hline$g_{\text {s-nitial }}\left[\mathrm{mol}\left(\mathrm{H}_{2} \mathrm{O}\right) \mathrm{m}^{-2} \mathrm{~s}^{-1}\right]$ & $0.014 \pm 0.003$ & $0.022 \pm 0.005$ & 0.214 \\
$g_{\text {s-max }}\left[\mathrm{mol}\left(\mathrm{H}_{2} \mathrm{O}\right) \mathrm{m}^{-2} \mathrm{~s}^{-1}\right]$ & $0.099 \pm 0.015$ & $0.244 \pm 0.006$ & $<0.001$ \\
$\mathrm{~T}_{90-\mathrm{gs}}[\mathrm{min}]$ & $23.5 \pm 1.3$ & $23.0 \pm 0.8$ & 0.742 \\
$\mathrm{~T}_{90-\mathrm{PN}}[\mathrm{min}]$ & $22.8 \pm 2.1$ & $16.0 \pm 1.0$ & 0.016 \\
$\mathrm{~T}_{90-\mathrm{JT}}[\mathrm{min}]$ & $15.2 \pm 1.2$ & $10.7 \pm 1.1$ & 0.020 \\
\hline
\end{tabular}




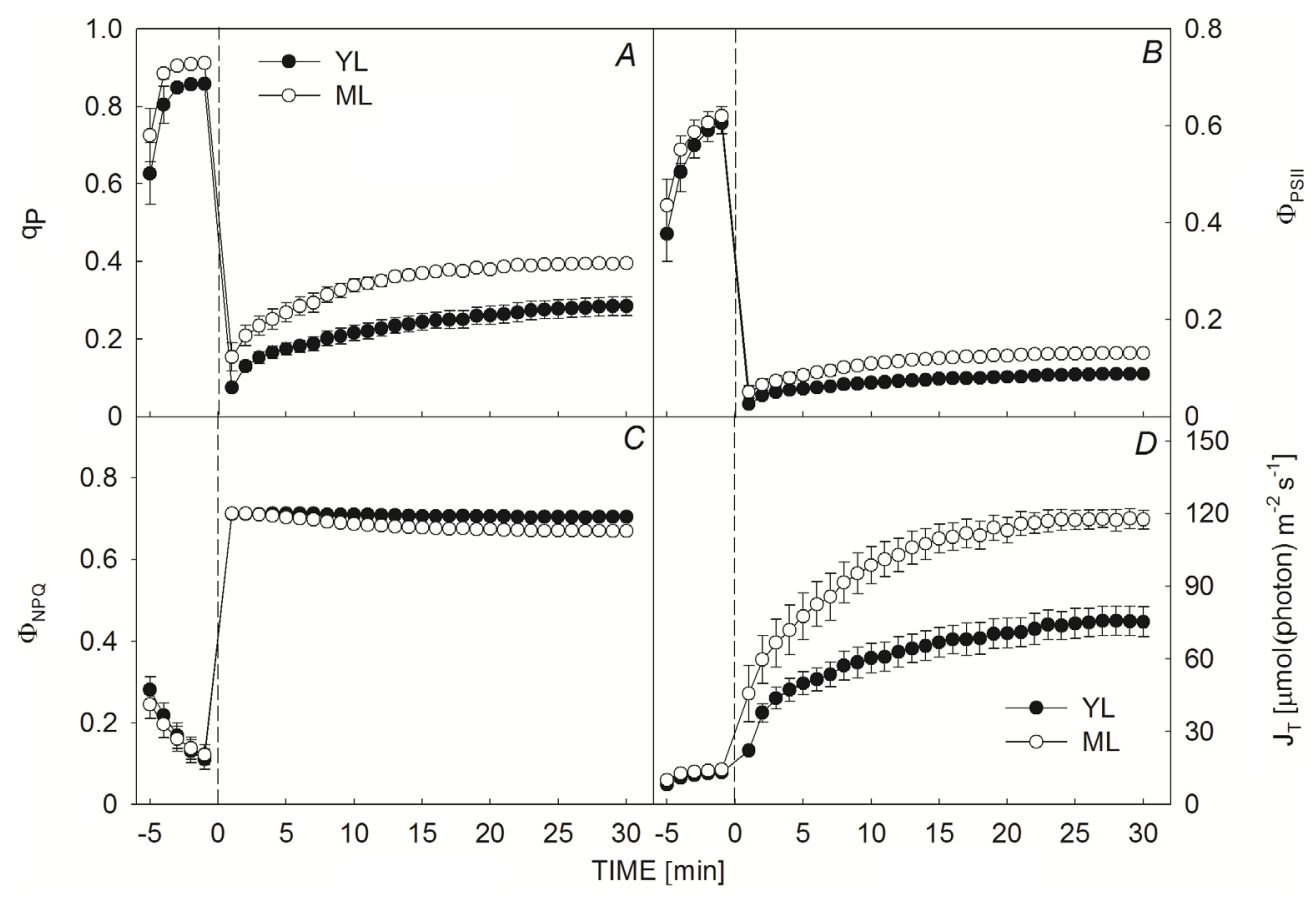

Fig. 3. Comparisons of photochemical quenching coefficient $\left(\mathrm{q}_{\mathrm{P}}\right)(A)$, actual photochemical efficiency of PSII $\left(\Phi_{\mathrm{PSII}}\right)(B)$, proportion of dissipation of excess light energy into harmless heat $\left(\Phi_{\mathrm{NPQ}}\right)(C)$, and total electron flow $\left(\mathrm{J}_{\mathrm{T}}\right)(D)$ during photosynthetic induction in young leaves (YLs) and mature leaves (MLs) of Chromolaena odorata. Values are means $\pm \mathrm{SE}(n=6)$.

during initial induction, there was far less SL than BL for both YLs and MLs (Fig. 4A,B). BL is the main limiting factor during the initial induction, however, it decreased with the photosynthetic induction proceeding. Therefore, photosynthetic induction in this invader is held back by a mix of biochemical limitation and stomatal limitation.

In the study, leaves were acclimated to darkness overnight prior to photosynthetic measurements. It has been shown that prolonged dark adaptation can lead to the full inactivation of photosynthetic enzymes in leaves (Kirschbaum et al. 1997), and when exposed to a darklight transition, photosynthetic enzymes need to be reactivated (Soleh et al. 2016). In addition, photosynthetic pigments and enzymes accumulate gradually from YLs to MLs (Jeong et al. 2004, Chondrogiannis and Grammatikopoulos 2016, Zhu et al. 2016). Previous research has indicated that the speed of photosynthetic induction response was positively correlated with Rubisco activase abundance (Mott et al. 1997, Tanaka et al. 2019). In this study, the estimation of Rubisco content may not correspond to the actual Rubisco content but indicates the relative content of activated Rubisco. The estimated Rubisco content of YLs was significantly lower than that of MLs (Table 1), which indicated a low relative content of activated Rubisco (Hymus et al. 2002). The development of pigments and enzymes in MLs have the capacity to enhance the photosynthetic capacity, as indicated by the higher $\mathrm{V}_{\mathrm{cmax}}$ and $\mathrm{J}_{\max }$ values observed in MLs. Furthermore, as a result of the maturity of the photosynthetic apparatus during leaf expansion, BL was removed more quickly in MLs than that in YLs (Fig. 4B). The higher relative content of activated Rubisco and pigments and enzymes in MLs promoted a rapid response of photosynthesis to a strong PPFD compared to YL.

\section{Rapid activation of NPQ in initial induction}

When exposed to a simulated sunfleck, both MLs and YLs activated maximum $\Phi_{\mathrm{NPQ}}$ in a stepwise manner (Fig. 3C). This result strongly supported our second hypothesis. The rapid activation of NPQ is likely an essential mechanism for dissipating excess light energy under simulated sunflecks.

Previous studies have shown that there is a time lag between onset of a sunfleck to achievement of $P_{\text {Nmax }}$ (Allen and Pearcy 2000, Bai et al. 2008, Martins et al. 2013, Chen et al. 2016). This time lag may lead to excess excited electrons, at least temporarily, during photosynthetic induction (Watling et al. 1997, Tausz et al. 2005). More recently, it has been noted that the activation of NPQ is accompanied by a high $\Delta \mathrm{pH}$ across the thylakoid membrane (Huang et al. 2017, Zhang and Zhang 2017). During initial induction, the photochemical efficiency is very low for both YLs and MLs, but NPQ is activated rapidly, which promotes the acidification of thylakoid lumen and subsequent activation of $\mathrm{q}_{\mathrm{E}}$ (Li et al. 2002, Živčák et al. 2014, Yamori 2016). The $\mathrm{q}_{\mathrm{E}}$ component of NPQ can regulate light-dependent reactions under high-intensity light, thereby protecting PSII from photoinhibition (Li et al. 2002, Yamori 2016). This mechanism also decreases the electron flow from the cytochrome $b_{6} / f$ complex (Cyt $b_{6} / f$ ) to PSI, which prevents the overreduction of PSI (Tikkanen and Aro 2014, Yamori and Shikanai 2016).

During initial induction, we observed a similar NPQ 


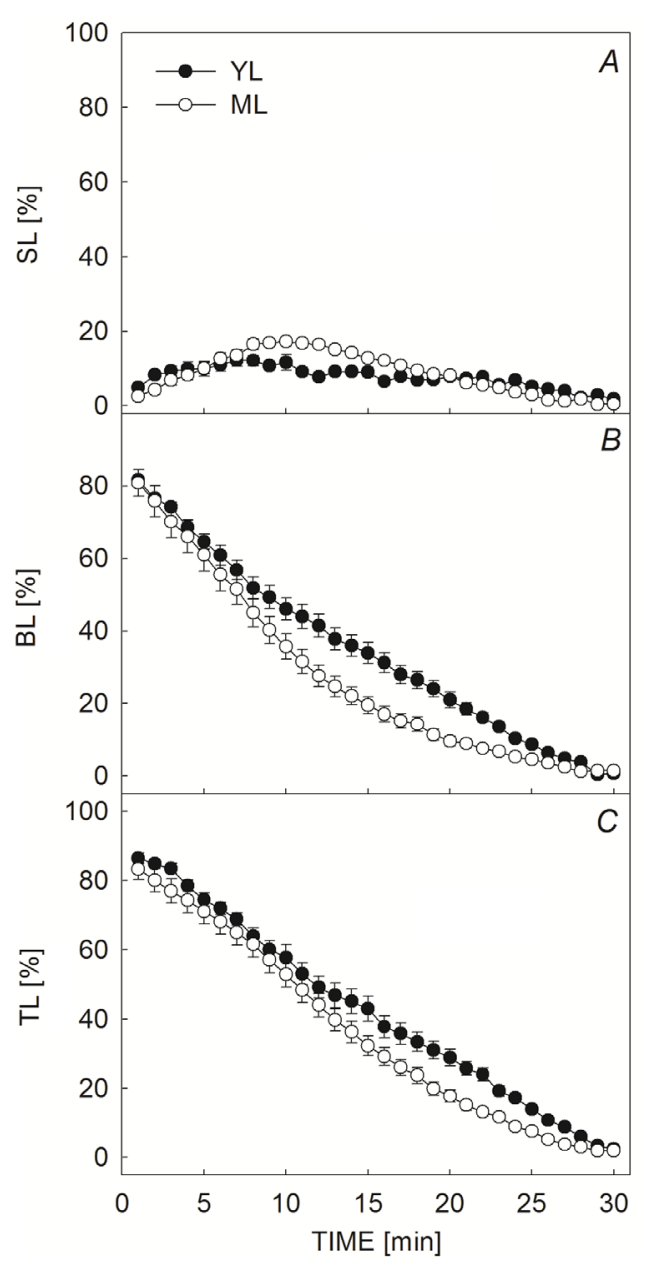

Fig. 4. The time course of stomatal limitation (SL) (A), biochemical limitation (BL) $(B)$, and total limitation (TL) $(C)$ to photosynthesis during photosynthetic induction in young leaves (YLs) and mature leaves (MLs) of Chromolaena odorata. Values are means $\pm \operatorname{SE}(n=6)$.

activation state for YLs and MLs; however, as photosynthetic induction proceeded, the light energy associated with photochemistry $\left(\mathrm{q}_{\mathrm{P}}\right)$ increased more rapidly in MLs than that in YLs (Fig. 3A). The simulated sunfleck used in this study was $2,000 \mu$ mol(photon) $\mathrm{m}^{-2} \mathrm{~s}^{-1}$, a value far higher than the LSP for YL $\left[560.7 \mu\right.$ mol(photon) $\mathrm{m}^{-2} \mathrm{~s}^{-1}$, Table 1]. In order to cope with the excess light energy during $30 \mathrm{~min}$ of exposure to sunfleck, YL maintained a constantly high NPQ. In contrast, NPQ decreased in MLs as photochemical quenching increased (Fig. $3 C$ ). Due to the immaturity of photosynthetic machinery, $\mathrm{q}_{\mathrm{P}}$ was lower in YLs than that in MLs (Fig. 3A), which indicates that YLs must dissipate more excess light energy than MLs. The differences in the activation of NPQ between YLs and MLs indicate a strong feedback regulation of excited electrons under sunflecks.

Conclusions: Our results strongly suggest that YLs responded more slowly to strong PPFDs than MLs. This is a result of higher induction limitations to photosynthesis in YLs than that in MLs. YLs have immature photosynthetic machinery, thus, the efficient dissipation of excess light energy may be more important than carbon gain during photosynthetic induction. These processes compensated for the low photochemical efficiency and promoted photoprotection in YLs. In natural environments, the productivity and growth of whole plants depend not only on steadystate photosynthesis, but also on dynamic photosynthesis (Yamori 2013, 2016). These findings highlight the photosynthetic mechanisms in leaves of light-demanding invaders in response to strong PPFDs. More attention should be focused on the photosynthetic response of leaves under fluctuating light in order to better understand the adaptive photosynthetic strategies of these invasive plants.

\section{References}

Allen M.T., Pearcy R.W.: Stomatal versus biochemical limitations to dynamic photosynthetic performance in four tropical rainforest shrub species. - Oecologia 122: 479-486, 2000.

Bai K.D., Liao D.B., Jiang D.B., Cao K.F.: Photosynthetic induction in leaves of co-occurring Fagus lucida and Castanopsis lamontii saplings grown in contrasting light environments. - Trees 22: 449-462, 2008.

Bertamini M., Nedunchezhian N.: Photoinhibition of photosynthesis in mature and young leaves of grapevine (Vitis vinifera L.). - Plant Sci. 164: 635-644, 2003.

Chazdon R.L.: Sunflecks and their importance to forest understorey plants. - Adv. Ecol. Res. 18: 1-63, 1998.

Chen J.W., Kuang S.B., Long G.Q. et al.: Steady-state and dynamic photosynthetic performance and nitrogen partitioning in the shade-demanding plant Panax notoginseng under different levels of growth irradiance. - Acta Physiol. Plant. 36: 2409-2420, 2014.

Chen J.W., Kuang S.B., Long G.Q. et al.: Photosynthesis, light energy partitioning, and photoprotection in the shadedemanding species Panax notoginseng under high and low level of growth irradiance. - Funct. Plant Biol. 43: 479-491, 2016.

Chondrogiannis C., Grammatikopoulos G.: Photosynthesis in developing leaf of juveniles and adults of three Mediterranean species with different growth forms. - Photosynth. Res. 130: 427-444, 2016.

Farquhar G.D., von Caemmerer S., Berry J.A.: A biochemical model of photosynthetic $\mathrm{CO}_{2}$ assimilation in leaves of $\mathrm{C}_{3}$ species. - Planta 149: 78-90, 1980.

Genty B., Briantais J.M., Baker N.R.: The relationship between the quantum yield of photosynthetic electron transport and quenching of chlorophyll fluorescence. - BBA-Gen. Subjects 990: 87-92, 1989.

Huang W., Hu H., Zhang S.B.: Photorespiration plays an important role in the regulation of photosynthetic electron flow under fluctuating light in tobacco plants grown under full sunlight. - Front. Plant Sci. 6: 621, 2015.

Huang W., Yang Y.J., Zhang S.B.: Specific roles of cyclic electron flow around photosystem I in photosynthetic regulation in immature and mature leaves. - J. Plant Physiol. 209: 76-83, 2017.

Hymus G.J., Snead T.G., Johnson D.P. et al.: Acclimation of photosynthesis and respiration to elevated atmospheric $\mathrm{CO}_{2}$ in two Scrub Oaks. - Glob. Change Biol. 8: 317-328, 2002.

Jackson B.R., Woodrow I.E., Mott K.A.: Nonsteady-state photosynthesis following an increase in photon flux density (PFD).Plant Physiol. 95: 498-503, 1991.

Jeong M.L., Jiang H.Y., Chen H.S. et al.: Metabolic profiling of 
the sink-to-source transition in developing leaves of quaking aspen. - Plant Physiol. 136: 3364-3375, 2004.

Joliot P., Johnson G.N.: Regulation of cyclic and linear electron flow in higher plants. - P. Natl. Acad. Sci. USA 108: $13317-$ 13322, 2011.

Kaiser E., Morales A., Harbinson J.: Fluctuating light takes crop photosynthesis on a rollercoaster ride. - Plant Physiol. 176: 977-989, 2018.

Kirschbaum M.U.F., Küppers M., Schneider H. et al.: Modelling photosynthesis in fluctuating light with inclusion of stomatal conductance, biochemical activation and pools of key photosynthetic intermediates. - Planta 204: 16-26, 1997.

Kobayashi T., Masuda K.: Induction of photosynthesis and importance of limitations during the induction phase in sun and shade leaves of five ecologically contrasting tree species from the temperate zone. - Tree Physiol. 27: 1207-1215, 2007.

Krall J.P., Edwards G.E.: Relationship between photosystem II activity and $\mathrm{CO}_{2}$ fixation in leaves. - Physiol. Plantarum 86: 180-187, 1992.

Krause G.H., Virgo A., Winter K.: High susceptibility to photoinhibition of young leaves of tropical forest trees. Planta 197: 583-591, 1995.

Li X.P., Müller-Moulé P., Gilmore A.M., Niyogi K.K.: PsbSdependent enhancement of feedback de-excitation protects photosystem II from photoinhibition. - P. Natl. Acad. Sci. USA 99: 15222-15227, 2002.

Long S.P., Bernacchi C.J.: Gas exchange measurements, what can they tell us about the underlying limitations to photosynthesis? Procedures and sources of error. - J. Exp. Bot. 54: 2393-2401, 2003.

Martins S.C.V., Detmann K.C., Reis J.V.D. et al.: Photosynthetic induction and activity of enzymes related to carbon metabolism: Insights into the varying net photosynthesis rates of coffee sun and shade leaves. - Theor. Exp. Plant Phys. 25: 62-69, 2013.

McAlpine K.G., Jesson L.K., Kubien D.S.: Photosynthesis and water-use efficiency: A comparison between invasive (exotic) and non-invasive (native) species. - Austral Ecol. 33: 10-19, 2008.

Mott K.A., Snyder G.W., Woodrow I.E.: Kinetics of Rubisco activation as determined from gas-exchange measurements in antisense plants of Arabidopsis thaliana containing reduced levels of Rubisco activase. - Aust. J. Plant Physiol. 24: 811-818, 1997.

Müller P., Niyogi K.K.: Non-photochemical quenching. A response to excess light energy. - Plant Physiol. 125: 1558-1566, 2001.

Munekage Y., Hashimoto M., Miyake C. et al.: Cyclic electron flow around photosystem I is essential for photosynthesis. Nature 429: 579-582, 2004.

Munekage Y., Hojo M., Meurer J. et al.: PGR5 is involved in cyclic electron flow around photosystem I and is essential for photoprotection in Arabidopsis. - Cell 110: 361-371, 2002.

Pearcy R.W.: Sunflecks and photosynthesis in plant canopies. Annu. Rev. Plant Biol. 41: 421-453, 1990.

Pearcy R.W., Gross L.J., He D.: An improved dynamic model of photosynthesis for estimation of carbon gain in sunfleck light regimes. - Plant Cell Environ. 20: 411-424, 1997.

Pearcy R.W., Krall J.P., Sassenrath-Cole G.F.: Photosynthesis in fluctuating light environments. - In: Baker N.R. (ed.): Photosynthesis and the Environment. Pp. 321-346. Springer, Dordrecht 1996.

Pearcy R.W., Seemann J.R.: Photosynthetic induction state of leaves in a soybean canopy in relation to light regulation of ribulose-1,5-bisphosphate carboxylase and stomatal conductance. - Plant Physiol. 94: 628-633, 1990.
Prioul J.L., Chartier P.: Partitioning of transfer and carboxylation components of intracellular resistance to photosynthetic $\mathrm{CO}_{2}$ fixation: A critical analysis of the methods used. - Ann. Bot.London 41: 789-790, 1977.

Qin R.M., Zheng Y.L., Valiente-Banuet A. et al.: The evolution of increased competitive ability, innate competitive advantage, and novel biochemical weapons act in concert to promote invasion for a tropical invader. - New Phytol. 197: 979-988, 2013.

Quan G.M., Mao D.J., Zhang J.E. et al.: Response of invasive Chromolaena odorata, and two coexisting weeds to contrasting irradiance and nitrogen. - Photosynthetica 53: 419429, 2015.

Raimundo R.L.G., Fonseca R.L., Schachetti-Pereira R. et al.: Native and exotic distributions of siamweed (Chromolaena odorata) modeled using the genetic algorithm for rule-set production. - Weed Sci. 55: 41-48, 2007.

Ranjan S., Singh R., Singh M. et al.: Characterizing photoinhibition and photosynthesis in juvenile-red versus maturegreen leaves of Jatropha curcas L. - Plant Physiol. Bioch. 79: 48-59, 2014.

Soleh M.A., Tanaka Y., Nomoto Y. et al.: Factors underlying genotypic differences in the induction of photosynthesis in soybean Glycine $\max ($ L.) Merr. - Plant Cell Environ. 39: 685-693, 2016.

Sperdouli I., Moustakas M.: Differential response of photosystem II photochemistry in young and mature leaves of Arabidopsis thaliana to the onset of drought stress. - Acta Physiol. Plant. 34: 1267-1276, 2012.

Sperdouli I., Moustakas M.: Differential blockage of photosynthetic electron flow in young and mature leaves of Arabidopsis thaliana by exogenous proline. - Photosynthetica 53: 471-477, 2015.

Tanaka Y., Adachi S., Yamori W.: Natural genetic variation of the photosynthetic induction response to fluctuating light environment. - Curr. Opin. Plant Biol. 49: 52-59, 2019.

Tausz M., Warren C.R., Adams M.A.: Dynamic light use and protection from excess light in upper canopy and coppice leaves of Nothofagus cunninghamii in an old growth, cool temperate rainforest in Victoria, Australia. - New Phytol. 165: 143-155, 2005.

Tikkanen M., Aro E.M.: Integrative regulatory network of plant thylakoid energy transduction. - Trends Plant Sci. 19: 10-17, 2014.

Urban O., Šprtová M., Košvancová M. et al.: Comparison of photosynthetic induction and transient limitations during the induction phase in young and mature leaves from three poplar clones. - Tree Physiol. 28: 1189-1197, 2008.

Watling J.R., Robinson S.A., Woodrow I.E., Osmond C.B.: Responses of rainforest understorey plants to excess light during sunflecks. - Aust. J. Plant Physiol. 24: 17-25, 1997.

Way D.A., Pearcy R.W.: Sunflecks in trees and forests: From photosynthetic physiology to global change biology. - Tree Physiol. 32: 1066-1081, 2012.

Woodrow I.E., Mott K.A.: Rate limitation of non-steady-state photosynthesis by ribulose-1,5-bisphosphate carboxylase in spinach. - Aust. J. Plant Physiol. 16: 487-500, 1989.

Yamori W.: Improving photosynthesis to increase food and fuel production by biotechnological strategies in crops. - J. Plant Biochem. Physiol. 1: 1000113, 2013.

Yamori W.: Photosynthetic response to fluctuating environments and photoprotective strategies under abiotic stress. - J. Plant Res. 129: 379-395, 2016.

Yamori W., Evans J.R., von Caemmerer S.: Effects of growth and measurement light intensities on temperature dependence of $\mathrm{CO}_{2}$ assimilation rate in tobacco leaves. - Plant Cell 
Environ. 33: 332-343, 2010.

Yamori W., Makino A., Shikanai T.: A physiological role of cyclic electron transport around photosystem I in sustaining photosynthesis under fluctuating light in rice. - Sci. Rep. 6: 20147, 2016.

Yamori W., Masumoto C., Fukayama H., Makino A.: Rubisco activase is a key regulator of non-steady-state photosynthesis at any leaf temperature and, to a lesser extent, of steady-state photosynthesis at high temperature. - Plant J. 71: 871-880, 2012.

Yamori W., Shikanai T.: Physiological functions of cyclic electron transport around Photosystem I in sustaining photosynthesis and plant growth. - Annu. Rev. Plant Biol. 67: 81-106, 2016.

Yan K., Peng C., Shao H.B. et al.: Photosynthetic characterization of Jerusalem artichoke during leaf expansion. - Acta Physiol. Plant. 34: 353-360, 2012.

Zhang J.L., Meng L.Z., Cao K.F.: Sustained diurnal photosynthetic depression in uppermost-canopy leaves of four dipterocarp species in the rainy and dry seasons: Does photorespiration play a role in photoprotection? - Tree Physiol. 29: 217-228, 2009.

Zhang S.B., Zhang J.L.: Variations in light energy dissipation in Woodfordia fruticosa leaves during expansion. Photosynthetica 55: 705-715, 2017.

Zheng Y.L., Feng Y.L., Zhang L.K. et al.: Integrating novel chemical weapons and evolutionarily increased competitive ability in success of a tropical invader. - New Phytol. 205: 1350-1359, 2015.

Zhu H., Zhang T.J., Zhang P., Peng C.L.: Pigment patterns and photoprotection of anthocyanins in the young leaves of four dominant subtropical forest tree species in two successional stages under contrasting light conditions. - Tree Physiol. 36: 1092-1104, 2016.

Živčák M., Kalaji H.M., Shao H.B. et al.: Photosynthetic proton and electron transport in wheat leaves under prolonged moderate drought stress. - J. Photoch. Photobio. B 137: 107115, 2014.

(C) The authors. This is an open access article distributed under the terms of the Creative Commons BY-NC-ND Licence. 